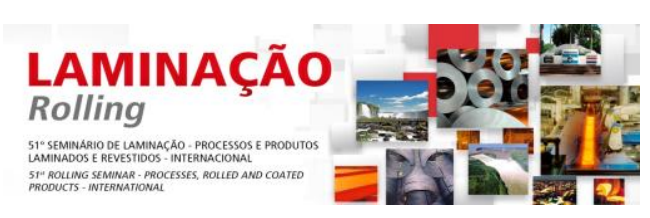

\title{
EVOLUÇÃO DO PROCESSO DE FABRICAÇÃO DE AÇO DA CSN PARA A INDÚSTRIA TAMBOREIRA: PROTETIVIDADE, LUBRICIDADE E COMPATIBILIDADE COM TINTAS E VERNIZES*
}

\author{
Ranieri Corrêa Salazar ${ }^{1}$ \\ Bárbara Oliveira Monteiro² \\ Roberto Teixeira Renó 3
}

\section{Resumo}

Essa contribuição técnica mostra a evolução do processo da Linha de Recozimento Contínuo de Chapas (LRCC\#1) da Companhia Siderúrgica Nacional (CSN), na produção de laminados a frio sem revestimento para o segmento de mercado de tambores.

A CSN vinha ao longo do tempo perdendo esse mercado devido principalmente a problemas de qualidade, como oxidação quando realizava a laminação de encruamento seca e, por outro lado quando processava o material com laminação de encruamento com óleo protetivo, ocorria no processo do cliente de cura a incompatibilidade com a tinta e vernizes nas aplicações mais críticas como acondicionamento alimentício, farmacêuticos e outros, cujos requisitos de qualidade rigorosos são exigidos contra qualquer tipo de contaminação. Desenvolveu-se um produto que associado ao controle de sua quantidade e a microgeometria da superfície da tira, resultou na lubricidade necessária para a continuidade operacional e atendeu aos requisitos de qualidade desejados.

Palavras-chave: Tambores; Óleo protetivo.

\section{EVOLUTION OF THE STEEL MANUFACTURING PROCESS OF THE CSN DRUM INDUSTRY: PROTECTIVITY, LUBRICITY AND COMPATIBILITY WITH PAINTS AND VARNISHES}

\section{Abstract}

This technical contribution shows the evolution of the process of Continuous Annealing Line (CAL \# 1) of the Companhia Siderúrgica Nacional (CSN), the production of cold-rolled uncoated for the market segment of drums. CSN came over time losing this market mainly due to quality problems such as oxidation performed when the lamination of dry skin pass and on the other side when processing the material with skin pass with protective oil, occurred in the client's healing process incompatibility with paint and varnish in critical applications such as food packaging, pharmaceuticals and others, whose requirements are stringent quality required against any kind of contamination. Developed a product associated with the control of its quantity and surface roughness of the strip, resulted in the lubricity required for operational continuity and met the requirements of desired quality.

Keywords: Drums; Protective oil.

1 Engenheiro Metalúrgico, Engenheiro de Desenvolvimento Sênior da Gerencia Geral de Galvanizados e Laminados a Frio da CSN, Volta Redonda, RJ, Brasil.

2 Engenheira Química, Engenheiro de Desenvolvimento Sênior da Gerencia Geral de Desenvolvimento de Produto da CSN, Volta Redonda, RJ, Brasil.

3 Engenheiro e Mestre em Engenharia Metalúrgica, gerente de produto da Quaker Chemical, Membro da ABM, Rio de Janeiro, RJ, Brasil.

* Contribuição técnica ao $51^{\circ}$ Seminário de Laminação - Processos e Produtos Laminados e Revestidos, 28 a 31 de outubro de 2014, Foz do Iguaçu, PR, Brasil. 


\section{INTRODUÇÃO}

Com o aumento da concorrência no setor siderúrgico e com visão de tornar cada vez mais competitivo os produtos laminados a frio da CSN, um fator importante é a conscientização das células de produção e manutenção para redução dos custos do produto acabado. Para isso se faz necessário uma reavaliação dos processos produtivos assim como uma visão do mercado.

É importante ressaltar, que para implantar tal iniciativa é necessário o comprometimento de todas as áreas envolvidas no processo em busca do resultado esperado.

Com a visão de oportunidades de mercado, esse trabalho está baseado no desenvolvimento de óleo protetivo para aços aplicados na fabricação de tambores, assim como melhorias no processo produtivo para fornecimento de bobinas/chapas isentas de defeitos de qualidade e que atenda aos requisitos de qualidade dos fabricantes e consumidores de tambor.

É um mercado que consome cerca de 5.500 .000 de tambores/ano e 84.000 toneladas/ ano de aço laminado a frio. Onde os principais fabricantes de tambor no Brasil são: GREIF, RAFT, MAUSER E GMM-METALBASA, conforme gráfico 1.

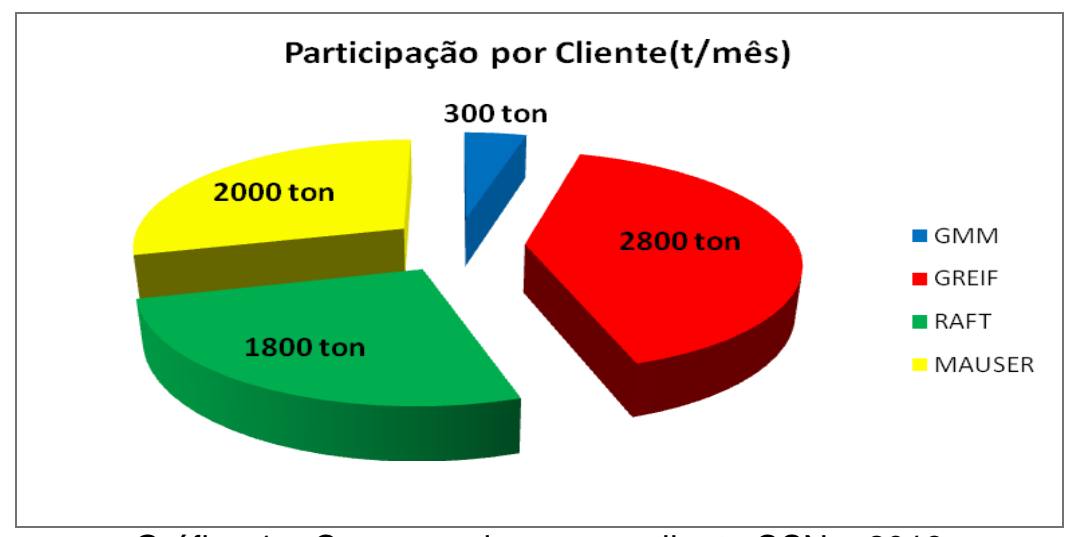

Gráfico 1 - Consumo de aço por cliente CSN - 2013

Em 2005, iniciou oficialmente esse desenvolvimento, onde foi aplicado pela primeira vez um óleo protetivo em bobinas que seriam destinadas a fabricação de tambores.

Naquela época foi constatado que o material fornecido pela CSN apresentava problemas de qualidade que afetavam a fabricação e a aplicação final dos tambores. Como o material era fornecido no estado "seco", isto é, sem aplicação de fluido anticorrosivo para proteção superficial, problemas de qualidade como oxidação e pontos de ferrugem eram frequentes, prejudicando o desempenho desse material nos clientes.

Além dos problemas de qualidade citados, os fabricantes dos tambores tinham muitas dificuldades no processamento do material CSN, tais como: falta de lubricidade, gerando agarramentos das chapas e as consequentes paradas na produção e problemas de travamento da prensa e o rompimento da peça conformada.

Para evitar o problema de falta de lubricidade, a aplicação de um fluido protetivo seria a medida capaz de garantir a proteção contra corrosão e a lubricidade necessária para o deslizamento da chapa na linha de produção. 


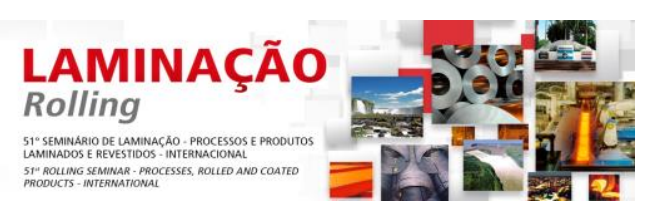

Entretanto, tal medida não foi suficiente para garantir a qualidade do produto final, pois a compatibilidade do fluido aplicado na superfície da chapa com os esmaltes (tintas) e vernizes é fator fundamental para sua aprovação na indústria Tamboreira, visto que não há na linha de produção desta indústria, qualquer etapa visando remoção do fluido protetivo para então realizar a pintura dos tambores. Deve-se ressaltar que a pintura é realizada diretamente na superfície como recebida da Siderúrgica, o que torna imprescindível uma superfície capaz de aceitar o revestimento orgânico, favorecendo sua ancoragem e acabamento superficial. A incompatibilidade do fluido com os revestimentos orgânicos (tintas e vernizes) gera um dos defeitos mais críticos na linha de pintura de tambores: o empolamento ou repelência da camada da tinta ou verniz que ocorre logo após a pintura ou após a etapa de cura. Além da compatibilidade resultante das interações entre as 2 entidades químicas: fluido anti-corrosivo e resina para pintura, a quantidade de fluido aplicado na superfície da chapa é outro fator determinante para o sucesso da superfície pintada, pois seu excesso pode também gerar tal defeito.

Em função do descrito acima, na presente contribuição, foi realizado o ajuste da composição do fluido protetivo à composição da resina, assim como a adequação do sistema de aplicação do fluido em consonância com o perfil da rugosidade de material.

Assim, este trabalho foi desenvolvido tendo como principais focos:

- Composição química do fluido protetivo

- Sistema de aplicação do fluido protetivo

- Acabamento da superfície

- Proteção superficial anticorrosiva

- Compatibilidade entre fluido anticorrosivo e revestimento orgânico

\section{IDENTIFICAÇÃO, OBSERVAÇÃO E ANÁLISE DO PROBLEMA}

Com o intuito de identificar a amplitude do problema, juntamente com nossa área comercial, foi identificado junto aos clientes o entendimento desse decréscimo no atendimento ao mercado. Foi constatado logo no início que o material fornecido pela CSN apresentava problemas de qualidade que afetariam a fabricação e a aplicação final dos tambores.

Como a CSN vinha fornecendo material "SECO", ou seja, sem proteção superficial, problemas de qualidade como oxidação e pontos de ferrugem, figura 1, apareciam constantemente, prejudicando o desempenho desse material no fabricante.

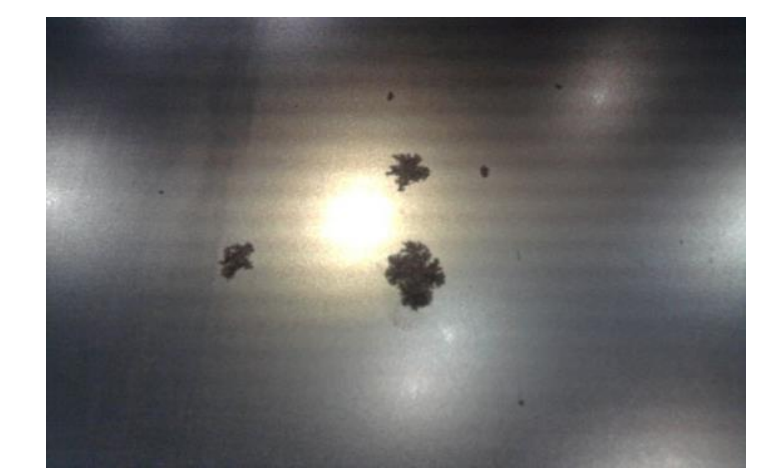

Figura 1 - Oxidação em material sem proteção superficial.

Além dos problemas de qualidade mencionados anteriormente, os fabricantes de tambores tinham muitas dificuldades com o material da CSN durante o processo.

* Contribuição técnica ao $51^{\circ}$ Seminário de Laminação - Processos e Produtos Laminados e Revestidos, 28 a 31 de outubro de 2014, Foz do Iguaçu, PR, Brasil. 


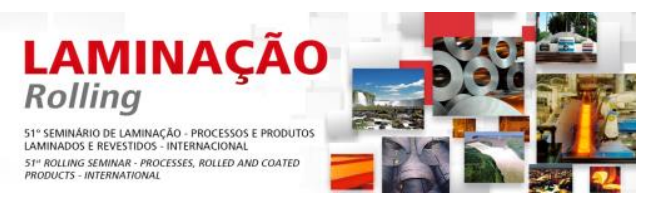

Como o material era fornecido seco, ele não apresentava uma lubricidade necessária que garantisse o perfeito deslizamento da chapa em determinadas partes da linha de produção, gerando agarramentos e paradas na produção.

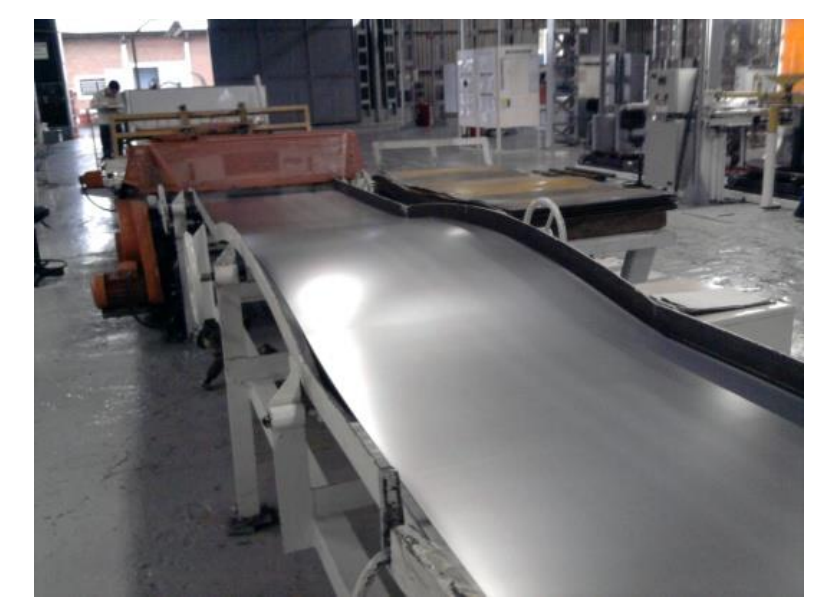

Figura 2- Agarramento de chapa em mesa de corte.

Esse agarramento, também se tornava um grande problema durante o processo de estampagem dos discos que posteriormente seriam utilizados na fabricação das tampas e fundos dos tambores, gerando problemas de travamento do equipamento e rompimento das peças estampadas.

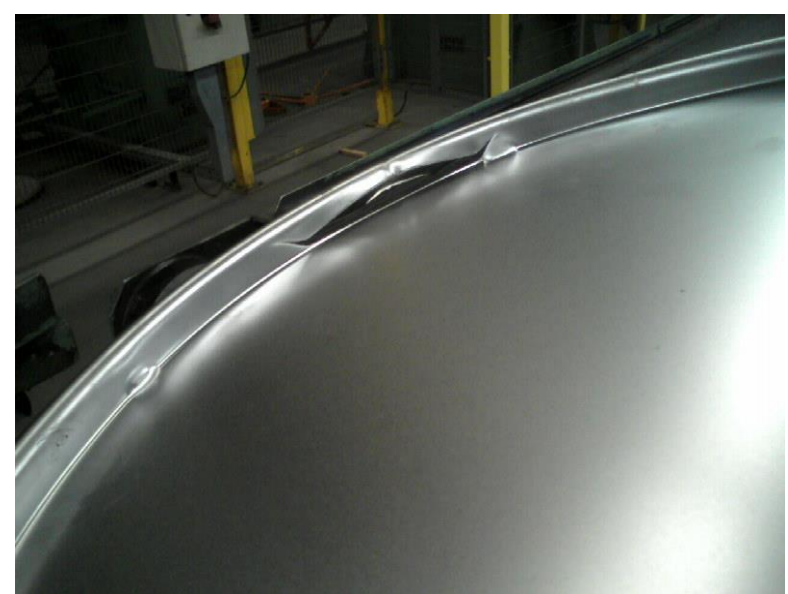

Figura 3 - Rompimento de peça estampada devido à falta de lubricidade.

O agarramento entre os esboços (blanks) no início do processo, na etapa de calandragem e solda dos cilindros, é outro grande problema, pois da mesma maneira, causa paradas na produção. O processo correto é puxar uma chapa por vez, e quando as ventosas, figura 4, levantam duas ou mais chapas de uma única vez, isso causa a interrupção na etapa de calandragem dos cilindros. 


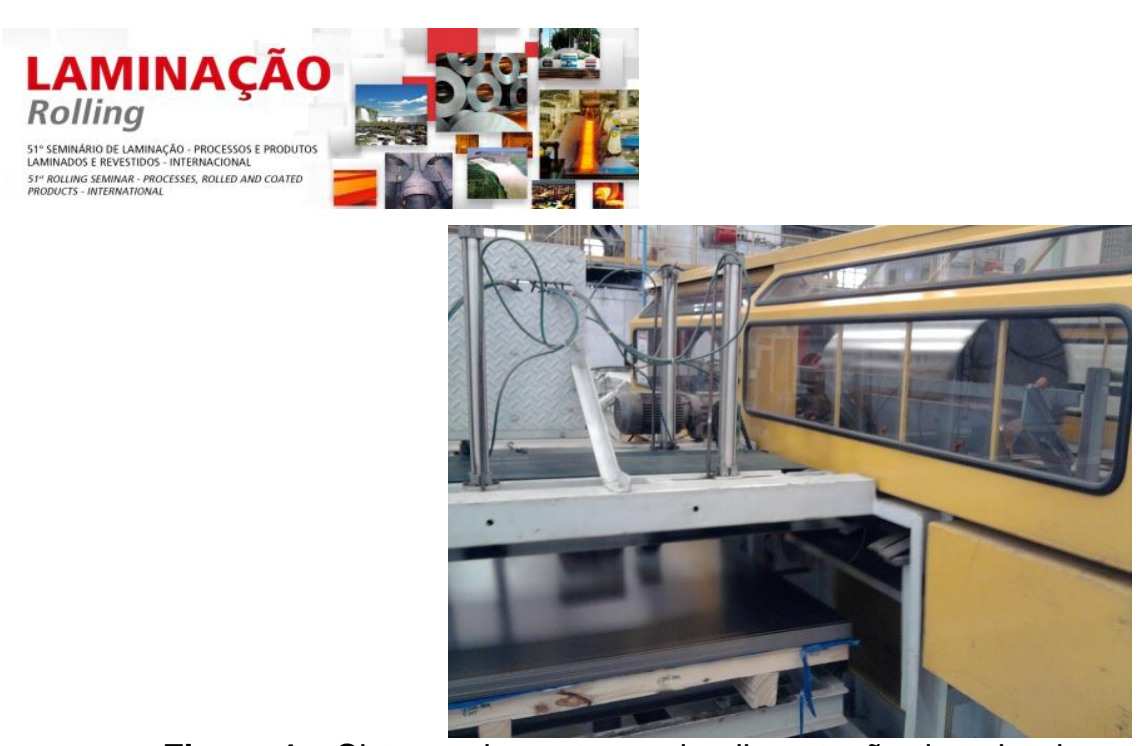

Figura 4 - Sistema de ventosas de alimentação da calandra e máquina de solda.

Para evitar tais problemas, a solução seria fornecer um material com uma camada de óleo protetivo que garanta a proteção superficial da chapa e o perfeito deslizamento da chapa na linha de produção. Porém, nos esbarramos em outro grande desafio que seria a compatibilidade de óleo aplicado na superfície da chapa com os esmaltes (tintas) e vernizes utilizados no processo de pintura dos tambores, uma vez, que as chapas não passam por um processo de desengraxe, limpeza antes de ser utilizada. Se o óleo aplicado não for compatível, outro problema de qualidade se apresenta, o empolamento ou repelência da camada de tinta (figura 6) ou verniz (figura 5) logo após a pintura ou após a etapa de cura.

Além da compatibilidade, a quantidade de óleo aplicado nessa superfície também deve ser controlada, pois o excesso pode causar os mesmos problemas causados pela incompatibilidade. Valores muito baixos de filme de óleo, em torno de $50 \mathrm{mg} / \mathrm{m}^{2}$ são exigidos para um processo de pintura ideal.

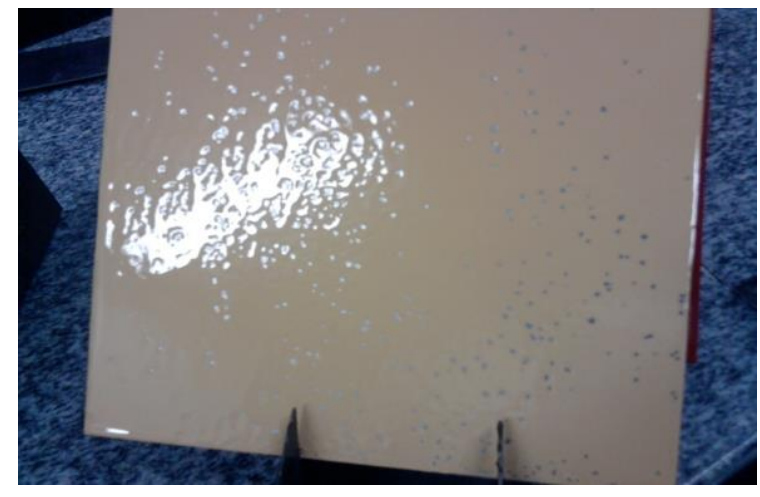

Figura 5 - Repelência - óleo x verniz.

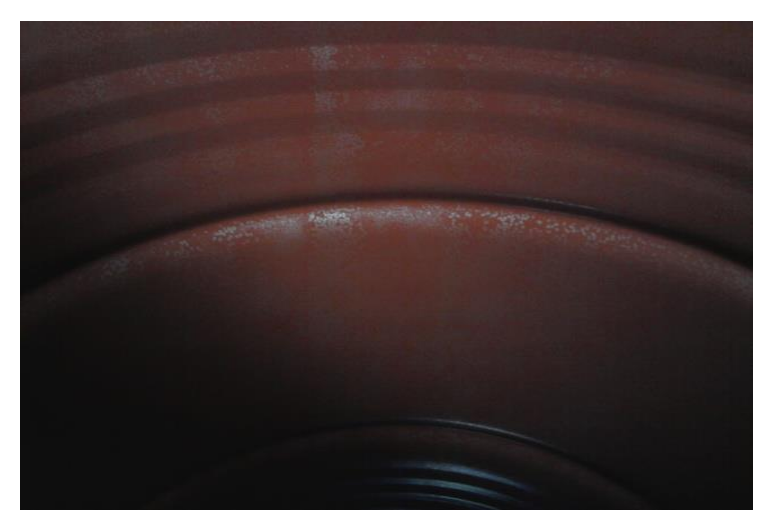

Figura 6 - Repelência - óleo x tinta.

\subsection{Desafios para o Atendimento}

Após a identificação e a observação das prováveis causas do problema, as ações foram nos seguintes fatores:

- Lubricidade na superfície da chapa

- Característica do lubrificante aplicado

- Superfície capaz de promover aderência

- Proteção superficial

- Atendimento aos requisitos de qualidade

* Contribuição técnica ao $51^{\circ}$ Seminário de Laminação - Processos e Produtos Laminados e Revestidos, 28 a 31 de outubro de 2014, Foz do Iguaçu, PR, Brasil. 


\section{MATERIAIS E MÉTODOS}

Após identificado os problemas a serem solucionados, fez-se o detalhamento dos mesmos.

- Lubricidade da chapa: Deslizamento das chapas no processo - permite processamento contínuo, sem interrupções.

- Característica do lubrificante aplicado: Compatibilidade com as tintas e vernizes (camadas aderentes, sem repelência, sem empolamento e sem manchas)

- Superfície capaz de promover aderência: Controle da gramatura máxima conforme óleo aplicado e garantir uma rugosidade superficial capaz de promover a aderência.

- Proteção superficial: Capacidade de proteção contra oxidação superficial

- Atendimento aos requisitos de qualidade: Garantir resultados positivos nos ensaios de aderência, mecânico, impacto, estanqueidade, camada de tinta/verniz

\section{ELABORAÇÃO DO PLANO DE AÇÃO}

A tabela 1 abaixo ilustra as ações estabelecidas para as soluções dos problemas identificados.

Tabela 1 - Plano de ação

\begin{tabular}{l|l|}
\multicolumn{1}{|c|}{ Principais Ações } & STATUS \\
\hline $\begin{array}{l}\text { Desenvolver óleo protetivo compatível com vernizes e } \\
\text { tintas aplicados no revestimento dos tambores }\end{array}$ & OK \\
$\begin{array}{l}\text { Desenvolver melhoria no sistema de oleamento do } \\
\text { laminador de encruamento \# } 5\end{array}$ & OK \\
\hline $\begin{array}{l}\text { Analisar quantidade de óleo aplicado na superfície da } \\
\text { chapa } \\
\text { Avaliar rugosidade na superfície da chapa }\end{array}$ & OK \\
\hline $\begin{array}{l}\text { Realizar testes em laboratório para garantir requisitos de } \\
\text { qualidade do cliente }\end{array}$ & OK \\
\hline $\begin{array}{l}\text { Realizar testes em escala industrial } \\
\text { Padronizar tipo de óleo para segmento tambores }\end{array}$ & OK \\
\hline
\end{tabular}

\subsection{Implantação das Ações Propostas}

Visando resolver os problemas de qualidade de agarramento e de qualidade (oxidação e pontos de ferrugem), iniciou-se a aplicação de óleo na chapa, porém os primeiros óleos testados eram compatíveis apenas com o esmalte (tinta) aplicado no lado externo dos tambores. O problema com o revestimento interno, onde o epóxifenólico era o mais crítico de se adequar um óleo protetivo com o verniz em termos de compatibilidade, pois um produto sem tal característica, o verniz não ancora de forma homogênea na superfície da chapa. 


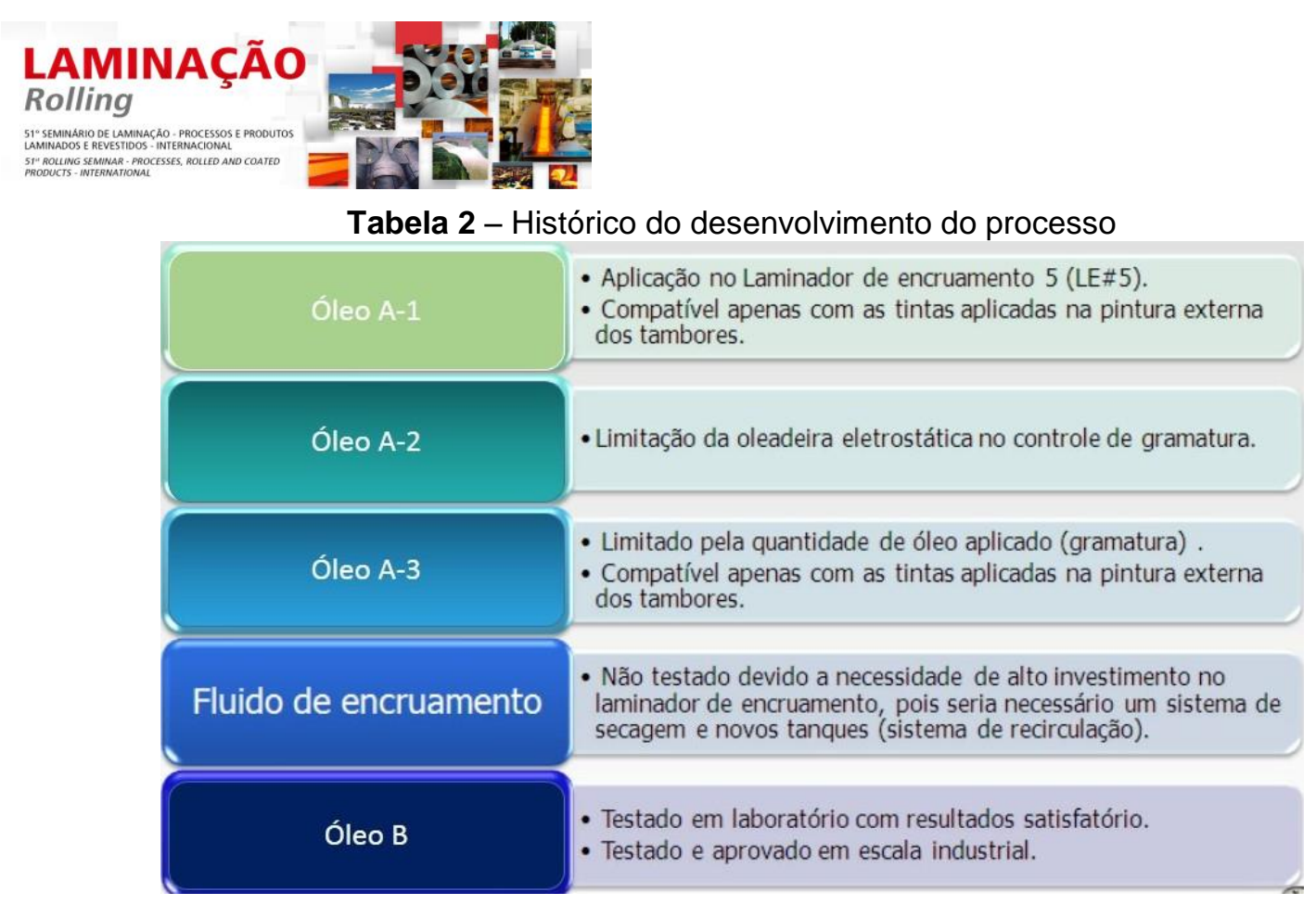

Após determinação do tipo de óleo compatível com os revestimentos aplicados nos tambores (tintas e vernizes), a questão passou a ser o controle da quantidade aplicada na superfície na chapa, pois em experimentos realizados em laboratório, observou-se que óleo em excesso provocava os mesmos efeitos de um óleo que não fosse compatível, ou seja, não ocorria a perfeita ancoragem e ocorria o que chamamos de repelência conforme figuras 5 e 6 .

Como o sistema do laminador de encruamento, não permitia um controle efetivo de gramatura por características de projeto do próprio sistema, onde esse sistema era composto de um reservatório de óleo, bomba de aplicação, bicos de aplicação e sistema de recirculação, conforme figura 7 , uma vez ligado o sistema, uma única vazão de óleo era aplicada sobre a tira independente da velocidade que a linha estivesse. Porém dessa maneira, se a linha estivesse a $30 \mathrm{mpm}$ ou a $220 \mathrm{mpm}$, a quantidade aplicada seria sempre a mesma. E assim, poderia ocorrer que em determinadas regiões de uma bobina estivesse com excesso de óleo e em outras regiões esse óleo fosse insuficiente.

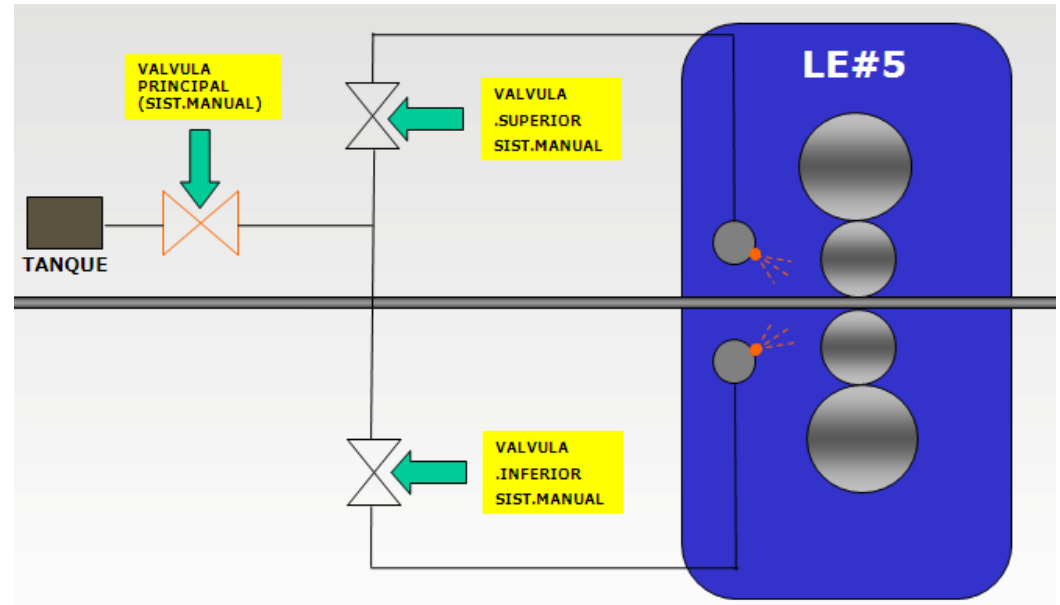

Figura 7 - Sistema de oleamento sem controle de vazão.

Para eliminar esta descontinuidade foi desenvolvido um sistema para controlar a vazão em função da velocidade da linha, pois dessa maneira, a camada de óleo 


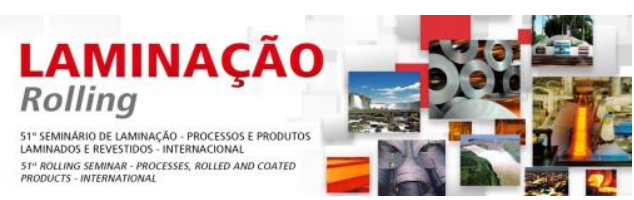

protetivo se apresentaria mais uniforme sem variação ao longo da bobina, o que poderia ser prejudicial para fabricação dos tambores.

Foi desenvolvido junto à equipe de manutenção um novo sistema com recursos próprios de materiais e mão de obra, onde foi utilizado amplificadores e válvulas controladoras para que a vazão seja uma relação com a velocidade da linha, conforme figura 8. Após instalação do sistema, ajustes refinados foram necessários para se obter uma camada homogênea de óleo ao longo de toda a extensão da bobina.

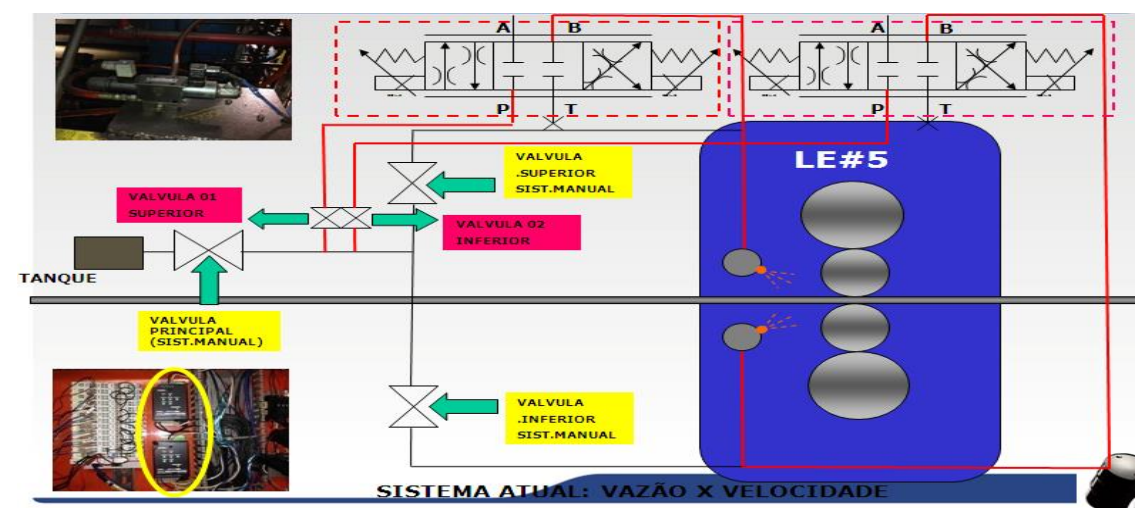

Figura 8 - Sistema de oleamento com controle de vazão.

Todas as medições de filme de óleo, foram realizadas conforme procedimento CSN. Todas as medições apresentaram valores baixo de filme de óleo, o que é ideal para atendimento aos clientes, conforme figura 9.

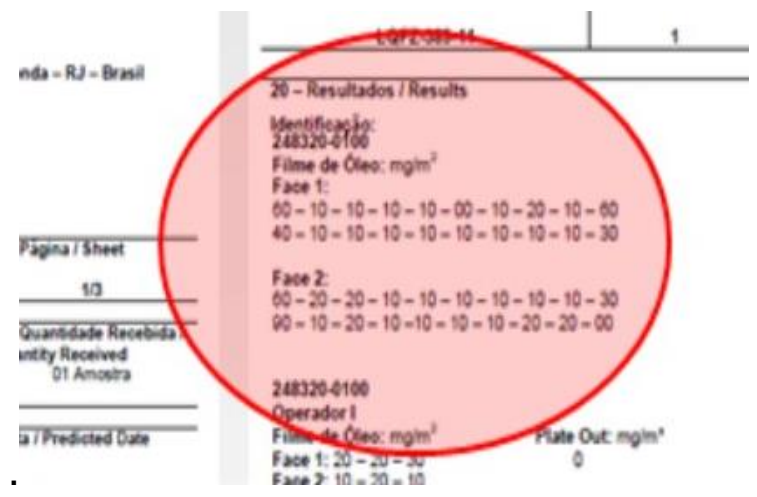

Figura 9 - Certificado CSN para análise de superfície.

Outro fator importante para a ancoragem da tinta ou verniz é a rugosidade da superfície onde esse produto será aplicado. Onde um perfil de rugosidade com picos elevados constitui num ponto propício ao aparecimento prematuro dos pontos de corrosão. Por outro lado uma rugosidade muito baixa pode prejudicar a aderência dos revestimentos aos substratos.

Portanto o acabamento de superfície ideal é aquele que resulta boas condições de aderência e boa cobertura dos picos do perfil da rugosidade. Nas figuras 10 e 11 observa-se o aspecto de uma camada ideal e a faixa de rugosidade satisfatória para a ancoragem, na faixa entre 0,60 a $1,50 \mu \mathrm{mRa}$, definida como rugosidade fosca [1]. 


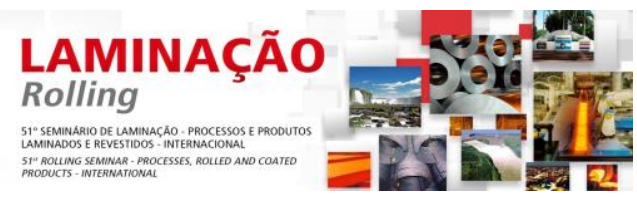

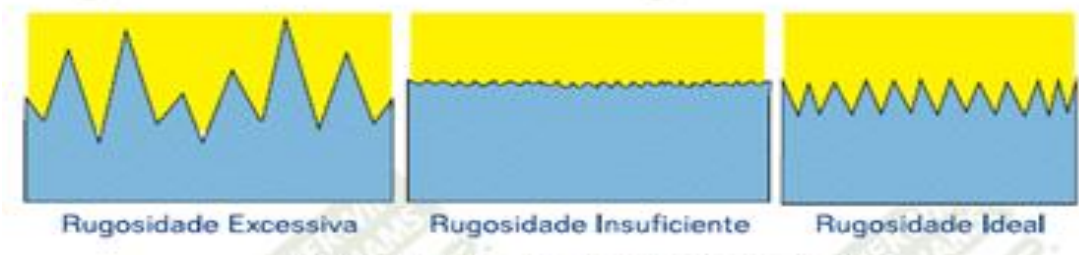

Altura do perfil $x$ Película seca de tinta

Figura 10 - Aspecto de rugosidade x película.

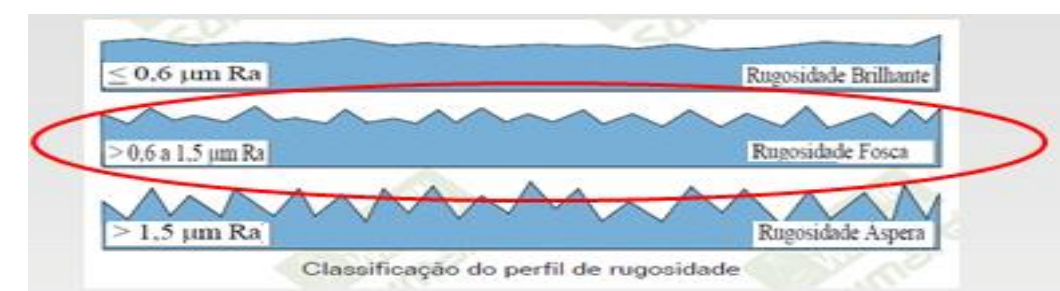

Figura 11 - Faixas de rugosidade em função do acabamento.

Como se trata de uma variável importante para o uso final durante a etapa de pintura, realizou-se uma análise de distribuição dos valores da rugosidade, como se nota na figura 12, valores estes que atenderam a qualidade do produto.

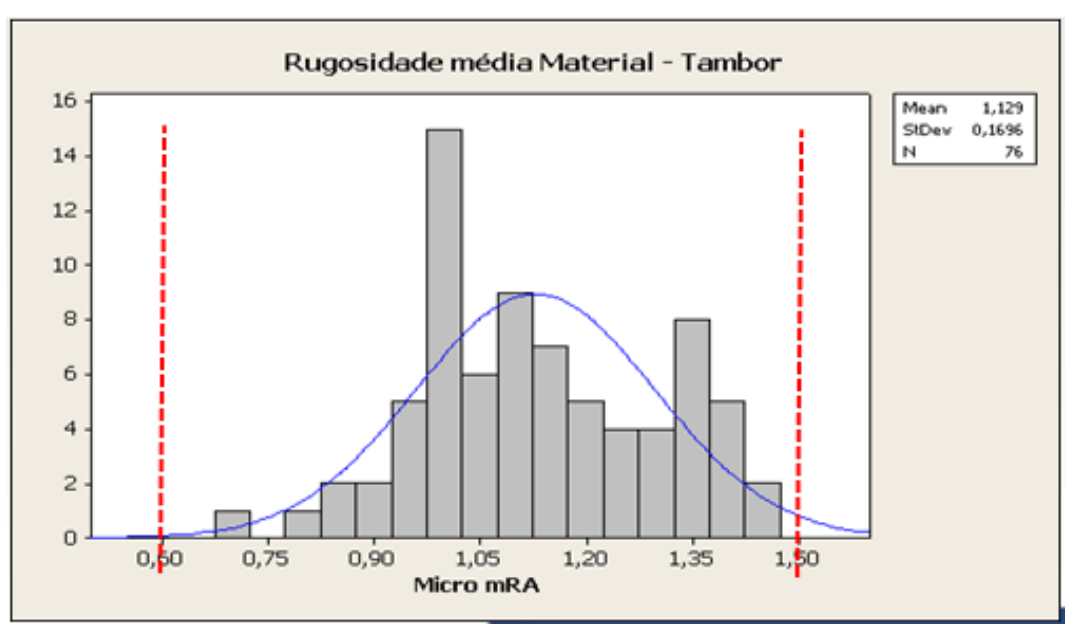

Figura 12 - Distribuição normal de rugosidade média do material tambor.

Após certificarmos que o óleo era compatível, a quantidade aplicada estava dentro dos limites aceitáveis e a rugosidade da chapa estava dentro da faixa ideal, foi efetuado os testes em laboratório, onde simulou as etapas de solda, pintura, cura da tinta e verniz, e os testes de qualidade para fabricação de tambores.

Os testes de qualidade foram: o teste da grade [2], onde uma série de riscos são feitos na chapa em forma de grade, conforme figura 13, e em seguida uma fita adesiva é colada sobre essa superfície e arrancada. Realiza-se uma análise dessa fita e é verificado se ocorreu desprendimento dos quadriculados de tinta ou verniz que estão situados entre os riscos. 

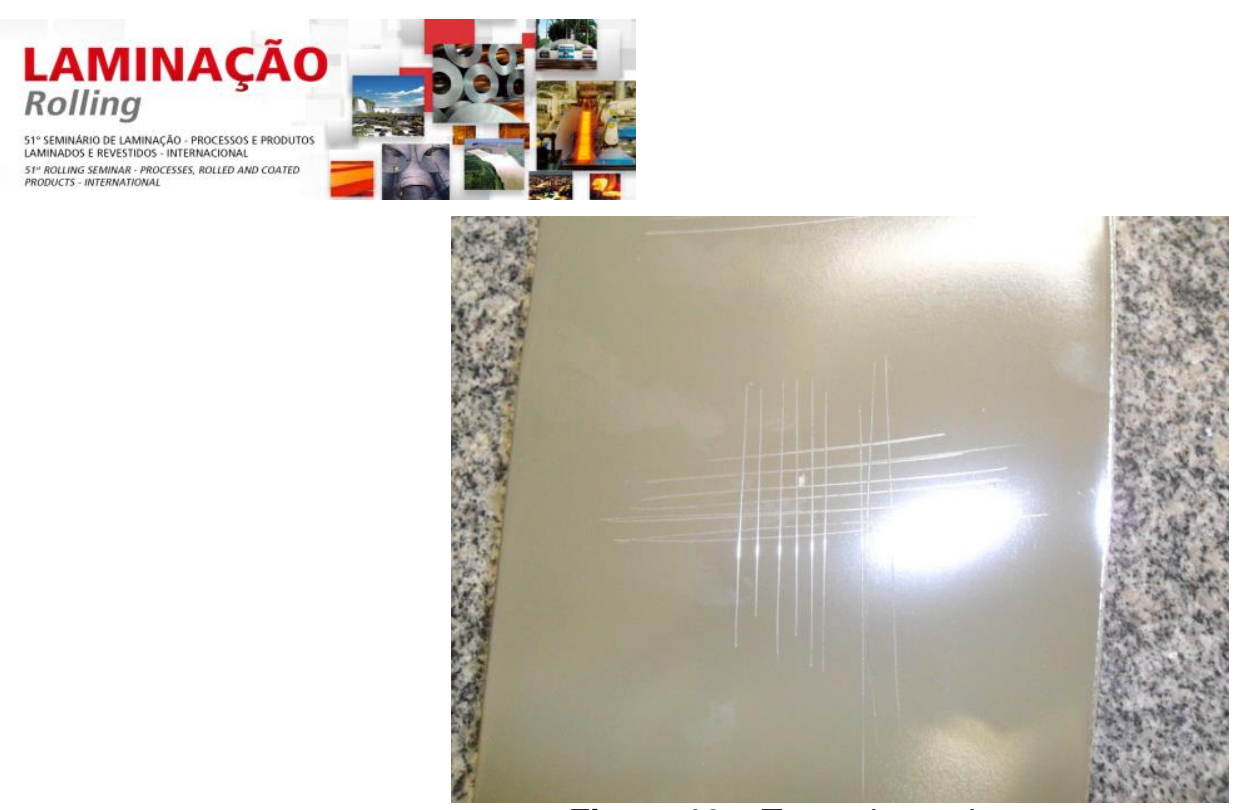

Figura 13 - Teste de grade.

Outro teste realizado é o teste de impacto, onde uma superfície já revestida é submetida ao impacto por um peso conforme norma. A análise é realizada verificando se o revestimento trinca ou quebra, conforme figura 14.

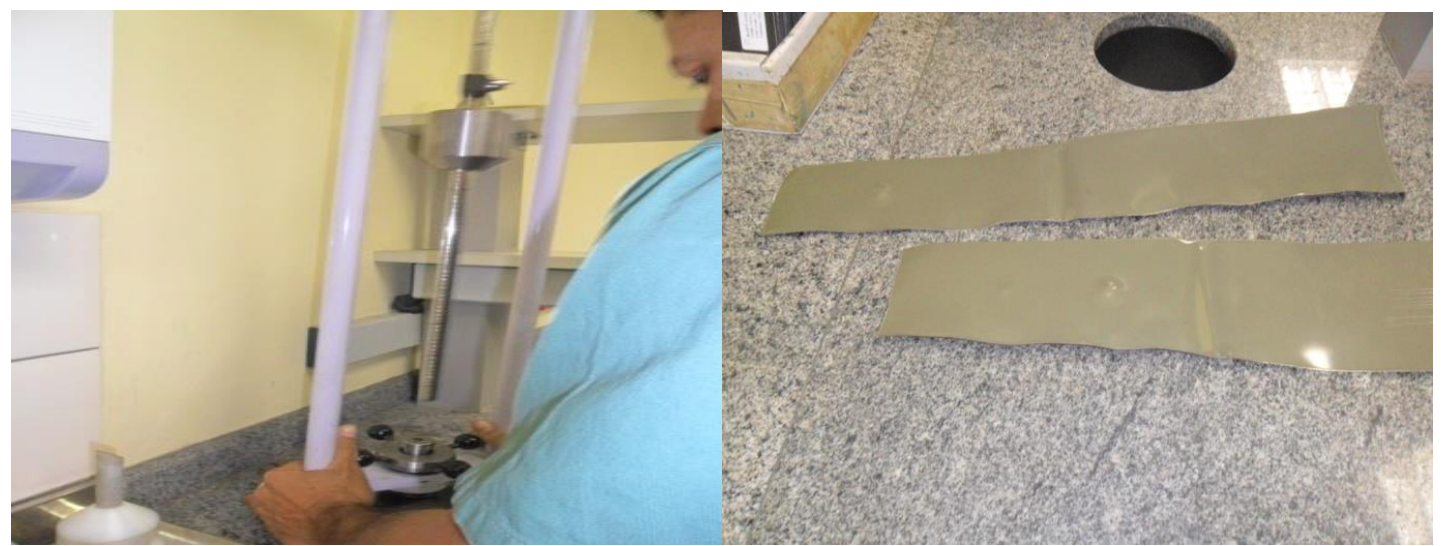

Figura 14 - Teste de impacto com peso padrão de $1 \mathrm{~kg}$.

O critério para aceitação é não trincar o revestimento, pois estamos simulando uma situação de queda ou impacto do tambor com amassamento das paredes.

Avaliação da camada de tinta ou verniz é realizada com o auxilio de um aparelho de ultrassom, além da avaliação visual para identificação de problemas no revestimento (Figuras 15 e 16).

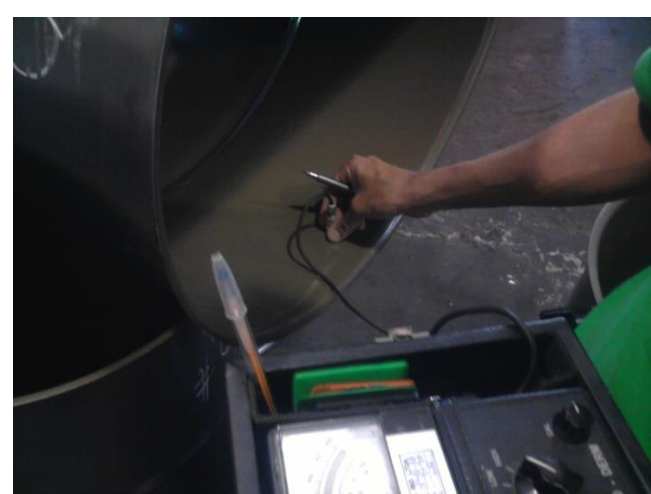

Figura 15 - Medição da camada de revestimento com ultra-som.

* Contribuição técnica ao $51^{\circ}$ Seminário de Laminação - Processos e Produtos Laminados e Revestidos, 28 a 31 de outubro de 2014, Foz do Iguaçu, PR, Brasil. 


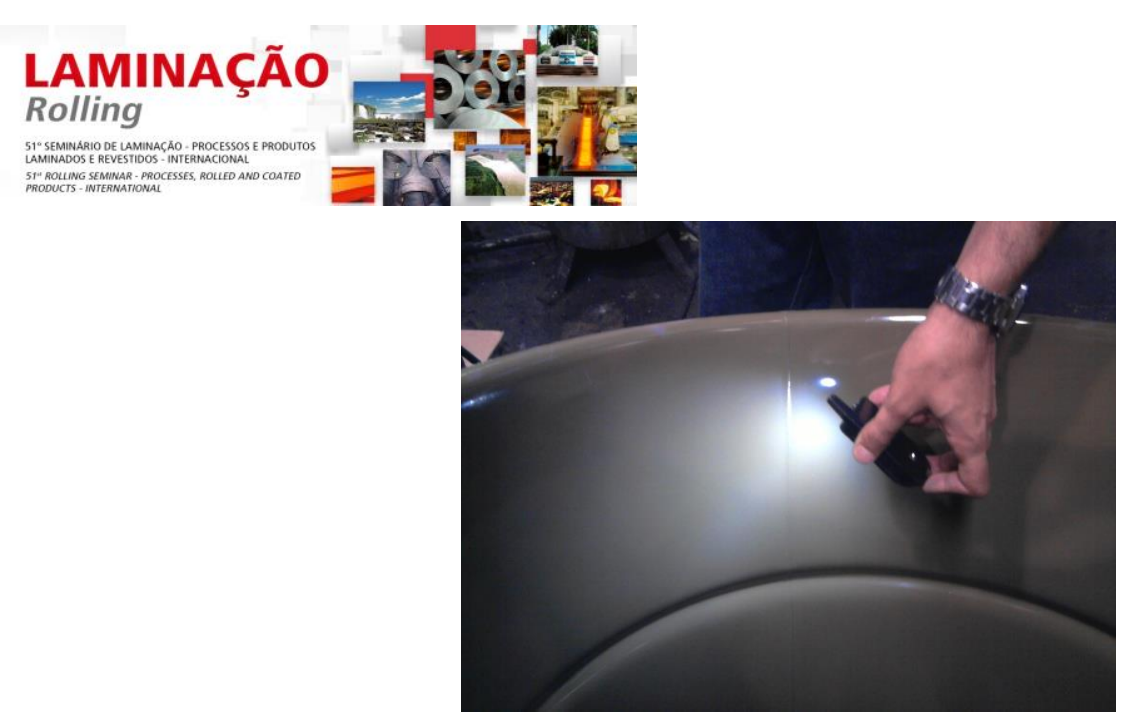

Figura 16 - Inspeção visual no produto final.

O último passo antes da liberação da produção do material na CSN foi a realização dos testes em escala industrial nos principais fabricantes de tambor, conforme figuras 17 e 18 de sequência de fabricação, onde os resultados finais foram satisfatórios para posterior homologação e liberação para produção em escala na CSN.

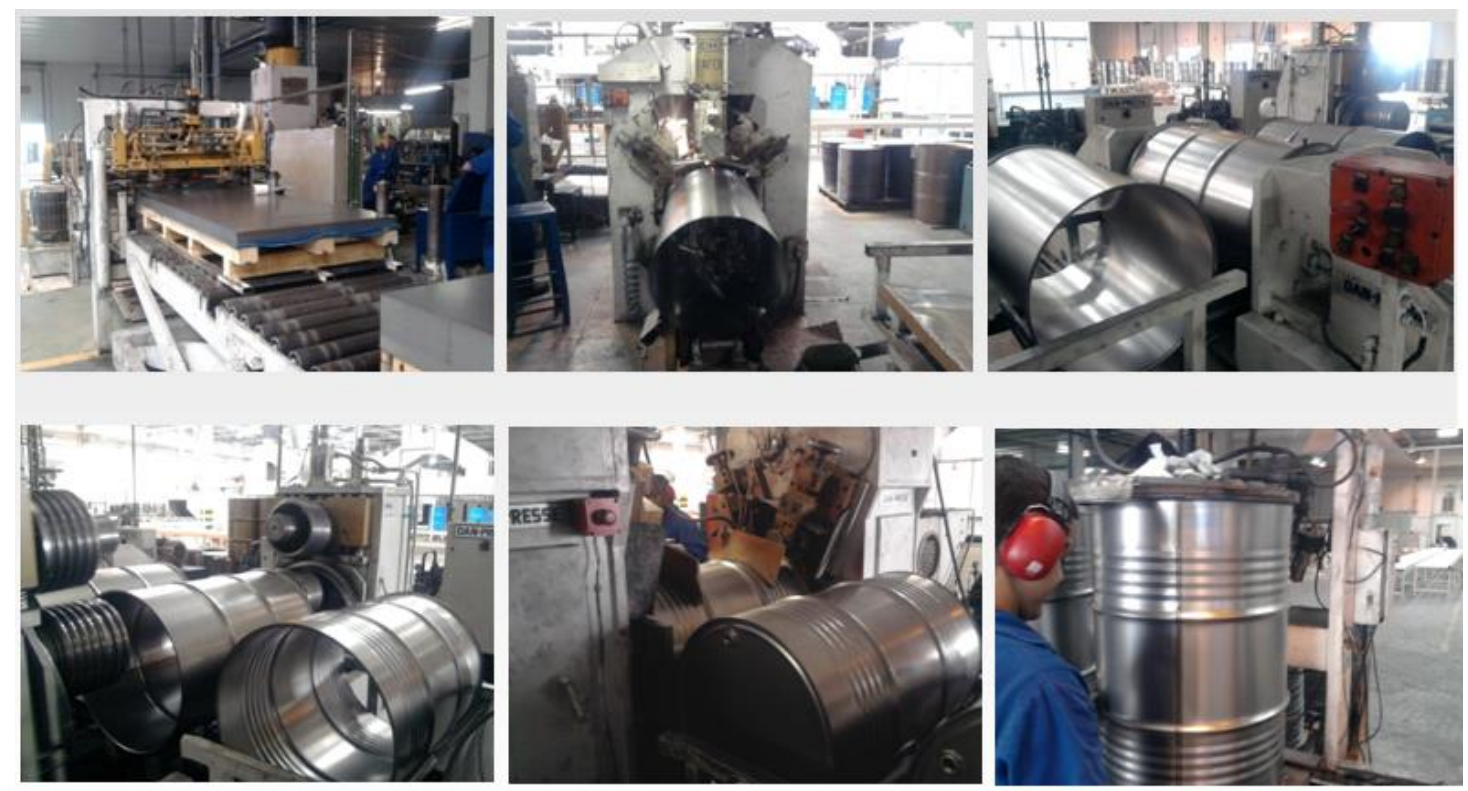

Figura 17- Sequência de fabricação 1. 

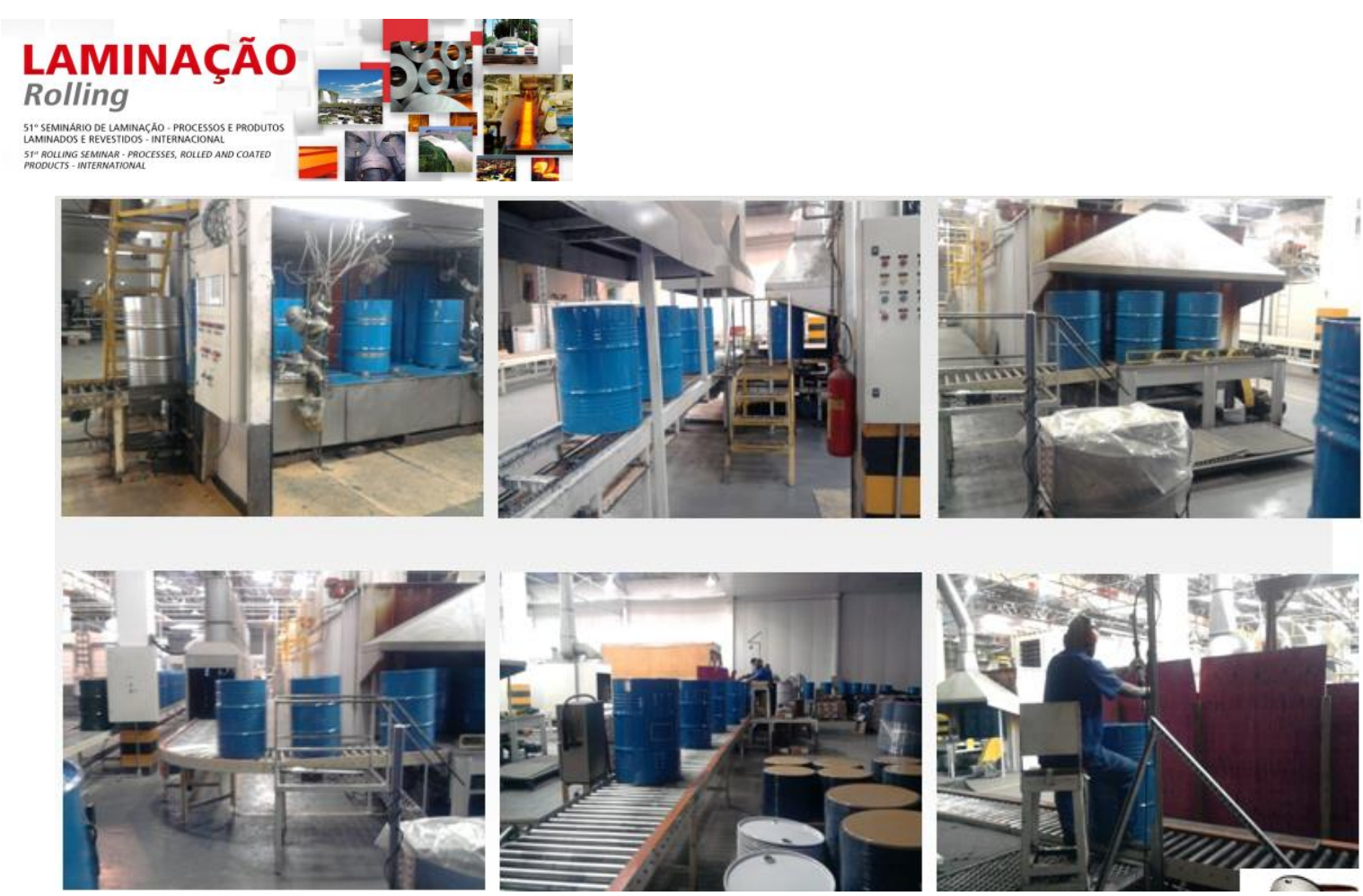

Figura 18 - Sequência de fabricação 2 (continuação).

Com todas as etapas do desenvolvimento concluídas com resultados satisfatórios, foi padronizado o tipo de óleo e gramatura a ser aplicado, assim, foram treinados todos os envolvidos nas atividades de fabricação do material destinado a fabricação de tambores.

\section{RESULTADOS E DISCUSSÃO}

Ao longo dos anos de desenvolvimento, conforme gráfico 2 , nota-se com 0 andamento das implantações o aumento gradativo do volume de material entregue.

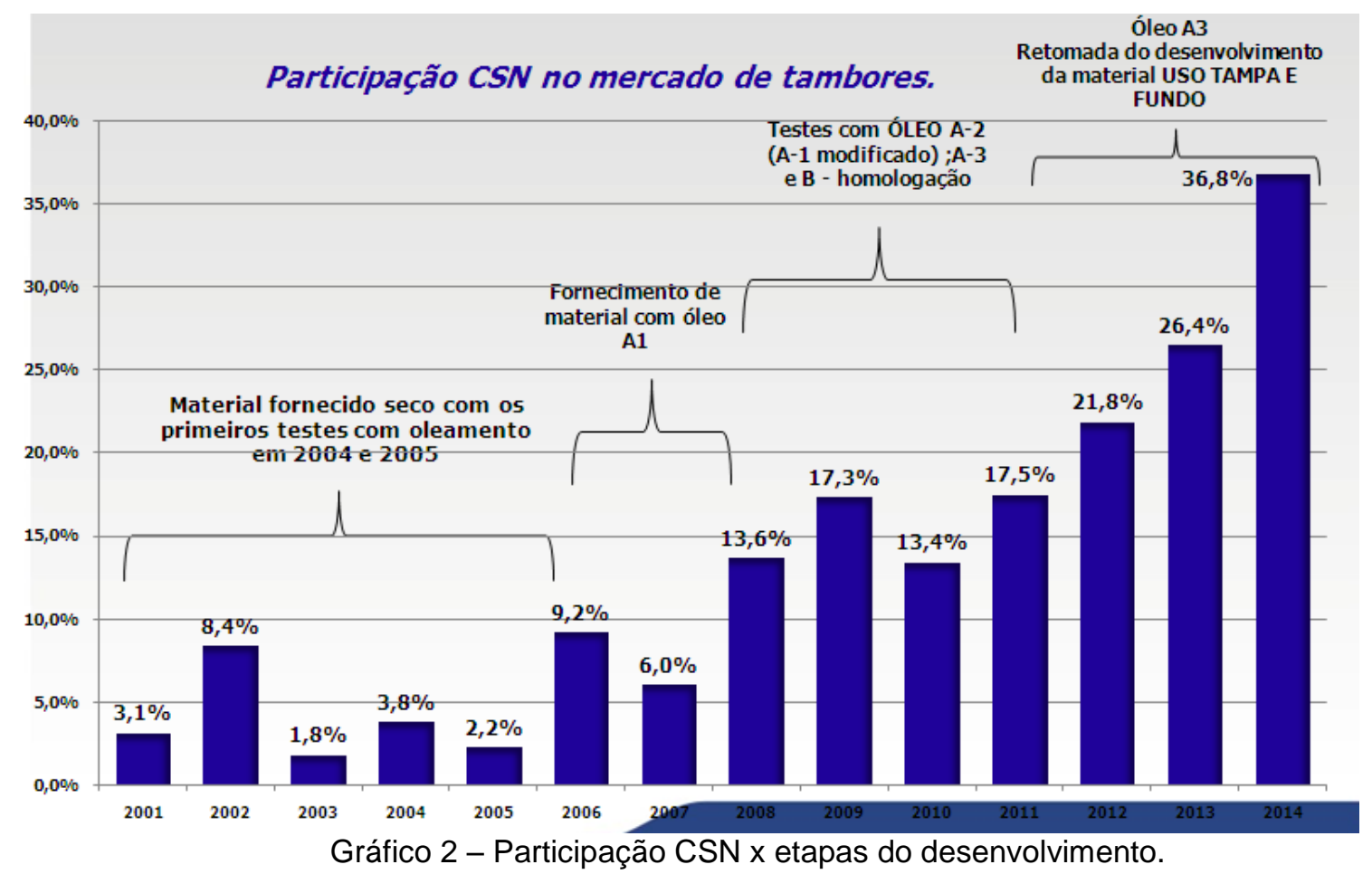

* Contribuição técnica ao $51^{\circ}$ Seminário de Laminação - Processos e Produtos Laminados e Revestidos, 28 a 31 de outubro de 2014, Foz do Iguaçu, PR, Brasil. 


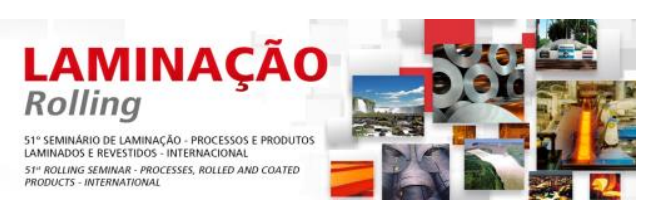

Além do aumento do volume entregue, o benefício financeiro foi outro fator importante para contribuir com os resultados da empresa, uma vez que a CSN estava praticamente fora desse mercado.

A melhora do desempenho do produto CSN nas empresas de beneficiamento de tambores por atender aos requisitos de qualidade e aumentar a produtividade dos nossos clientes, vem como um dos benefícios tecnológicos, pois a CSN hoje fornece um material isento de defeito de qualidade que possibilita 0 aumento de produtividade dos seus clientes. Com isso, a CSN tornou-se mais competitiva no segmento tambores, entregando um produto com maior resistência à corrosão e adequado ao sistema de pintura dos clientes tamboreiros.

\section{CONSIDERAÇÕES FINAIS}

- A compatibilidade do fluido aplicado na laminação de encruamento da tira laminada a frio com a resina a ser utilizada no processo de pintura interna do tambor é determinante na aderência e qualidade da mesma.

- A quantidade de fluido e a sua distribuição também é importante na qualidade da pintura.

- O acabamento de superfície das tiras laminadas é prejudicial a resistência à corrosão quando o perfil da rugosidade é excessivo e, quando insuficiente propicia a falta de aderência da camada de tinta. Na presente contribuição, o valor da rugosidade no critério $\mathrm{Ra}$ de 0,6 a 1,5 umRa foi satisfatório para não ocorrência destas não conformidades.

\section{REFERÊNCIAS}

1 Rugosidade - PNB 249

2 Teste da grade - ABNT NBR 11003 Tintas determinação da aderência - 2009

* Contribuição técnica ao $51^{\circ}$ Seminário de Laminação - Processos e Produtos Laminados e Revestidos, 28 a 31 de outubro de 2014, Foz do Iguaçu, PR, Brasil. 